\title{
CXCL5 as an autocrine or paracrine cytokine is associated with proliferation and migration of hepatoblastoma HepG2 cells
}

\author{
YANG YANG $^{1 *}$, JIE HOU $^{2 *}$, MINGLIANG SHAO $^{3}$, WEI ZHANG $^{3}$, YALING $^{4}{ }^{4}$, SHENGNAN E $^{1}$, \\ SHUQIU WANG ${ }^{1}$, HONGYU SUI ${ }^{1}$, DEXIN MENG ${ }^{1}$, BAIXIN WANG $^{1}$, MINGFU WANG $^{1}$, YANG HAN $^{2}$, \\ YU CAO ${ }^{2}$, XIAOQING HUANG ${ }^{1}$, YUE LI $^{1}$, PENGXIA ZHANG $^{1}$ and WEIQUN WANG ${ }^{1}$ \\ ${ }^{1}$ Basic Medical College, Jiamusi University, Jiamusi, Heilongjiang 154007; ${ }^{2}$ The First Affiliated Hospital, \\ Jiamusi University, Jiamusi, Heilongjiang 154002; ${ }^{3}$ The Fifth Hospital, Shijiazhuang, Hebei 050021; \\ ${ }^{4}$ Hainan Medical College, Haikou, Hainan 571199, P.R. China
}

Received February 29, 2016; Accepted August 10, 2017

DOI: $10.3892 / \mathrm{ol} .2017 .7236$

\begin{abstract}
C-X-C motif chemokine ligand 5 (CXCL5) is a CXC-type chemokine that is a crucial inflammatory mediator and a powerful attractant for granulocytic immune cells. Increasing evidence has indicated that CXCL5 is involved in the tumorigenesis of various malignancies. The present investigation demonstrated that CXCL5 was expressed in both hepatoblastoma HepG2 cells and liver stellate LX-2 cells, and CXCL5's receptor C-X-C chemokine receptor type 2 (CXCR2) was expressed in HepG2 cells by reverse transcription-polymerase chain reaction (RT-PCR), western blotting and ELISA assays. Cell counting kit-8, colony formation and Transwell assays revealed that exogenous CXCL5 expression efficiently promoted proliferation, colony formation and migration of HepG2 cells. To explore the autocrine and paracrine roles of CXCL5 in the oncogenic potential of HepG2 cells, HepG2 cells overexpressing CXCL5 and LX-2 cells overexpressing CXCL5 were successfully constructed by gene transfection. Similarly, overexpression of CXCL5 in HepG2 also enhanced proliferation, colony formation and migration of HepG2 cells. Furthermore, the condition medium of LX-2 cells overexpressing CXCL5 affected the proliferation and migration of HepG2 cells. RT-PCR and western blotting assays were also conducted to explore whether overexpression of CXCL5 in HepG2 modulated the expression of genes. The results revealed that overexpression of CXCL5 regulated the expression of several genes, including $\mathrm{N}$-myc downregulated
\end{abstract}

Correspondence to: Professor Weiqun Wang or Professor Pengxia Zhang, Basic Medical College, Jiamusi University, 148 Xuefu Street, Jiamusi, Heilongjiang 154007, P.R. China

E-mail: wangweiqun1974@163.com

E-mail: pengxiaz@163.com

${ }^{*}$ Contributed equally

Key words: C-X-C motif chemokine ligand 5, autocrine, paracrine, hepatoblastoma gene 3,w B-cell lymphoma-2 (Bcl-2), Bcl-2-associated X protein, P53, vascular endothelial growth factor, interleukin (IL)-18, IL-1 $\beta$ and cystathionine- $\gamma$-lyase. In conclusion, the present findings indicate that CXCL5/CXCR2 axis contributes to the oncogenic potential of hepatoblastoma via autocrine or paracrine pathways by regulating expression of genes associated with the progression of carcinoma.

\section{Introduction}

Hepatoblastoma (HB) is a prevalent malignancy among children, which histologically derives from pluripotent stem cells that may differentiate into liver cells and biliary epithelial cells, and accounts for almost two-thirds of pediatric malignant liver tumors $(1,2)$. Although the survival rate of HB has increased from 35 to $75 \%$ during the last 30 years with the application of surgical excision, adjuvant chemotherapy and liver transplantation (3), additional investigation of the underlying molecular mechanism will be beneficial for the improving diagnosis and treatment of patients with HB.

Previous studies have supported the hypothesis that the development of malignancies is closely associated with various cytokines, in which chemokines appear to have crucial roles. Chemokines are members of the cytokine super family and are secreted by various cell types, including immune, mesothelial, endometrial glandular and stromal cells, and trophoblasts (4). According to the order of conserved cysteine residues, chemokines are classified as $\mathrm{C}, \mathrm{CC}, \mathrm{CXC}$ and $\mathrm{C}(\mathrm{X})_{3} \mathrm{C}$. Additionally, $\mathrm{CXC}$ chemokines are further grouped into ELR ${ }^{+} \mathrm{CXC}$ and ELR CXC on the basis of the presence or absence of the amino-terminal ELR motif (5). In addition to their function in chemotaxis, chemokines can induce various activation progressions in physiology through their effects on regulating angiogenesis, cellular proliferation, differentiation and apoptosis (6-8). However, previous data have suggested that a variety of chemokines are also involved in the pathogenesis of malignancies. Milliken et al (9) reported that high expression of $\mathrm{C}-\mathrm{X}-\mathrm{C}$ motif chemokine ligand (CXCL) 8 in ovarian cancer epithelial cells resulted in an increased proliferation rate compared with low expression of CXCL8 in the cells. As an efficient mediator of angiogenesis, 
the expression of CXCL5 in non-small cell lung cancer was associated with angiogenesis, which is vitally important in the proliferation, invasion and metastasis of tumor cells (10). In prostatic carcinoma, CXCL12 contributes to the migration potential of tumor cells by activating the transcription of genes associated with the cytoskeleton, including microtubule associated protein RP/EB family member 3 and dedicator of cytokinesis 9 , and downregulating the expression of intercellular adhesion proteins, including cadherin-1 and $\beta$-catenin (11). The biological functions of chemokines rely mainly on their receptors, a type of $G$ protein-coupled receptor that mediates the functions of chemokines and is usually expressed in immune cells and endothelial cell membrane. Murakami et al (12) indicated that C-X-C chemokine receptor type 4 is an essential molecular determinant for the metastatic accumulation of tumor cells in the lungs of mice. The tumor homing hypothesis also showed that the specific combination of the chemokine ligand and its receptor is sufficient to initiate tumor metastasis (13). Previous studies have shown that overexpression of CXCL5 is present in numerous human tumors including prostate, squamous cell and stomach tumors. Additionally, CXCL5 may have an important role in the occurrence and progression of tumors by cooperating with its receptor $\mathrm{C}-\mathrm{X}-\mathrm{C}$ chemokine receptor type 2 (CXCR2) (14-16). Although a previous study by Zhou et al (17) demonstrated that the expression of CXCL5 in hepatocellular carcinoma tissues was evidently increased compared with that in para-carcinoma tissues and overexpression of CXCL5 can promote the growth and invasion of hepatocellular carcinoma cells, the effects of CXCL5 contributing to the growth and migration of HB cells through the autocrine/paracrine pathways have not, to the best of our knowledge, been reported. Therefore, the current study aimed to explore whether CXCL5 can affect the oncogenic potential of HB through autocrine and paracrine signaling.

\section{Materials and methods}

Cell culture. The human HB HepG2 cell and human hepatic stellate LX-2 cell lines were maintained in a $37^{\circ} \mathrm{C}$ humidified incubator at $5 \% \mathrm{CO}_{2}$ in Dulbecco's modified Eagle's medium (DMEM; Gibco; Thermo Fisher Scientific, Inc., Waltham, MA, USA) containing 10\% fetal bovine serum (FBS; Gibco; Thermo Fisher Scientific, Inc.), $100 \mathrm{U} / \mathrm{ml}$ penicillin and $100 \mathrm{U} / \mathrm{ml}$ streptomycin (DMEM complete medium).

Cell transfection. The lentiviral CXCL5 expression vector (pEZ-Lv203-A1113) and empty vector (pEZ-Lv203-NEG) were constructed by GeneCopoeia, Inc. (Rockville, MD, USA), which were utilized to prepare a DNA/EndoFectin Lenti complex, which were transfected into 293Ta lentiviral packaging cells (American Type Culture Collection, Manassas, VA, USA) using the Lenti-Pac ${ }^{\mathrm{TM}}$ HIV Expression Packaging kit (cat. no. HPK-LvRT-20; GeneCopoeia, Inc.) according to the manufacturer's protocol. After $48 \mathrm{~h}$ of transfection, the pseudovirus-containing culture medium was collected and purified by filtering the supernatant through $0.45 \mu \mathrm{m}$ low protein-binding filters. HepG2 and LX-2 cells were transfected by incubating them in DMEM complete medium with $50 \%$ diluted viral supernatant for $48 \mathrm{~h}$, following which fresh DMEM complete medium containing puromycin (Sigma-Aldrich; Merck KGaA, Darmstadt, Germany) at $2 \mathrm{ng} / \mathrm{ml}$ was added for selection. Cells were used for further experimentation 14 days after transfection.

Reverse transcription-polymerase chain reaction (RT-PCR) analysis. Total RNA was extracted from parental, empty vector-transfected, as well as CXCL5-transfected HepG2 and LX-2 cells with TRIzol reagent (Invitrogen; Thermo Fisher Scientific, Inc.) and first-strand cDNA was synthesized using Reverse Transcription System (cat. no. A3500; Promega Corporation, Madison, WI, USA). PCR primers were synthesized by Sangon Biotech Co., Ltd. (Shanghai, China), the primer sequences and conditions are presented in Tables I and II, respectively.

Western blot analysis for protein detection. The parental, empty vector-transfected, as well as CXCL5-transfected HepG2 cells pellets were harvested and western blot assays were performed as previously described (18). Anti-CXCR2 mouse polyclonal antibody (cat. no. sc-30008; dilution, 1:500; Santa Cruz Biotechnology, Inc., Dallas, TX, USA), anti-interleukin (IL)-18 rabbit polyclonal antibody (cat. no. sc-7954; dilution, 1:800; Santa Cruz Biotechnology, Inc.), anti-IL-1 $\beta$ rabbit polyclonal antibody (cat. no. YT2342; dilution, 1:1,000; ImmunoWay Biotechnology Company, Plano, TX, USA), anti-cystathionine- $\gamma$-lyase (CSE) rabbit polyclonal antibody (cat. no. BA3605; dilution, 1:800; Wuhan Boster Biological Technology, Ltd., Wuhan, China) and anti- $\beta$-actin mouse monoclonal antibody (cat. no. sc-130300; dilution, 1:3,000; Santa Cruz Biotechnology, Inc.) were utilized in the assays. Goat anti-rabbit IgG (cat. no. BA1054; dilution, 1:1,000; Wuhan Boster Biological Technology, Ltd.) and goat anti-mouse IgG (cat. no. BA1050; dilution, 1:1,000; Wuhan Boster Biological Technology, Ltd.) were used as secondary antibodies.

ELISA assays. Parental, empty vector-transfected, as well as CXCL5-transfected HepG2 and LX-2 cells were seeded in a 6 -well plate $\left(1.5 \times 10^{5}\right.$ cells/well $)$ with DMEM complete medium. After $48 \mathrm{~h}$ of incubation at $37^{\circ} \mathrm{C}$, the supernatants were collected and centrifuged at $22,000 \mathrm{x}$ g at $4^{\circ} \mathrm{C}$ for $15 \mathrm{~min}$. The secretion levels of CXCL5 were determined by ELISA using Human CXCL5 Elisa kit (cat. no. EK0728; Wuhan Boster Biological Technology, Ltd.), according to the manufacturer's protocol.

Cell proliferation assays. Cell Counting kit-8 (CCK-8; cat. no. AR1160-500; Wuhan Boster Biological Technology, Ltd.) was utilized to explore the effect of exogenous, autocrine or paracrine CXCL5 on HepG2 cell proliferation. HepG2 cells were seeded onto a 96 -well plate $\left(1.5 \times 10^{3}\right.$ cells/well $)$ with DMEM complete medium containing $0,20,40$ or $60 \mathrm{ng} / \mathrm{ml}$ exogenous recombinant human CXCL5 (PeproTech, Inc., Rocky Hill, NJ, USA), and proliferation activity was investigated after $24,48,72$ and $96 \mathrm{~h}$ incubation at $37^{\circ} \mathrm{C}$. To examine the autocrine effects of endogenous CXCL5, the parental, empty vector-transfected and CXCL5-transfected HepG2 cells were seeded onto a 96 -well plate $\left(2 \times 10^{3}\right.$ cells/well) with DMEM complete medium. The proliferation was then determined after $72 \mathrm{~h}$ incubation at $37^{\circ} \mathrm{C}$. In order to detect the 
Table I. Primer sequences used for reverse transcription-polymerase chain reaction.

\begin{tabular}{lll}
\hline Gene & \multicolumn{1}{c}{ Forward primer sequence, 5'-3' $^{\prime}$} & \multicolumn{1}{c}{ Reverse primer sequence, 5'-3' } \\
\hline$\beta$-actin & AGAAAATCTGGCACCACACC & CTCCTTAATGTCACGCACGA \\
CXCL5 & GCTACCACTTCCACCTTG & CCACTATGAGCCTVVTGT \\
CXCR2 & CAGGAATGTGGCCAAAAAT & GGAAACTCCCTCGTGATG \\
NDRG3 & GGCGAATTGTCCCCTACCACCAG & CTGCCTCCTGTTCTTACCCACCTA \\
Bcl-2 & CGAACTCAAAGAAGGCCACAAT & TGGGAGAACGGGGTACGATA \\
Bax & TGAGCACTCCCGCCACAAAG & TTGTCGCCCTTTCTACTTTGCC \\
P53 & TGCAATAGGTGTGCGTCAGAA & CCCCGGGACAAAGCAAA \\
& CAAATCTAGCCAGGAAACGACC & AAGGAGGAGGGCAGAATCATCACGA
\end{tabular}

Bcl-2, B-cell lymphoma-2; Bax, Bcl-2-associated X protein; VEGF, vascular endothelial growth factor; CXCL5, C-X-C motif chemokine ligand 5; CXCR2, C-X-C chemokine receptor type 2.

Table II. Reverse transcription-polymerase chain reaction conditions for each primer set.

\begin{tabular}{ll}
\hline Gene & \multicolumn{1}{c}{ Reaction conditions } \\
\hline 3-actin & $94^{\circ} \mathrm{C}$ for $3 \mathrm{~min}, 28$-cycles of $94^{\circ} \mathrm{C}$ for $30 \mathrm{sec}, 55^{\circ} \mathrm{C}$ \\
& for $25 \mathrm{sec}, 72^{\circ} \mathrm{C}$ for $1 \mathrm{~min}$ \\
CXCL5 & $94^{\circ} \mathrm{C}$ for $3 \mathrm{~min}, 28$-cycles of $94^{\circ} \mathrm{C}$ for $30 \mathrm{sec}, 55^{\circ} \mathrm{C}$ \\
& for $25 \mathrm{sec}, 72^{\circ} \mathrm{C}$ for $1 \mathrm{~min}$ \\
CXCR2 & $94^{\circ} \mathrm{C}$ for $3 \mathrm{~min}, 28$-cycles of $94^{\circ} \mathrm{C}$ for $30 \mathrm{sec}, 55^{\circ} \mathrm{C}$ \\
& for $25 \mathrm{sec}, 72^{\circ} \mathrm{C}$ for $1 \mathrm{~min}$ \\
Bcl-2 & $94^{\circ} \mathrm{C}$ for $3 \mathrm{~min}, 38$-cycles of $94^{\circ} \mathrm{C}$ for $30 \mathrm{sec}, 54^{\circ} \mathrm{C}$ \\
& for $35 \mathrm{sec}, 72^{\circ} \mathrm{C}$ for $1 \mathrm{~min}$ \\
Bax & $94^{\circ} \mathrm{C}$ for $3 \mathrm{~min}, 30$-cycles of $94^{\circ} \mathrm{C}$ for $30 \mathrm{sec}, 55^{\circ} \mathrm{C}$ \\
& for $30 \mathrm{sec}, 72^{\circ} \mathrm{C}$ for $1 \mathrm{~min}$ \\
P53 & $94^{\circ} \mathrm{C}$ for $3 \mathrm{~min}, 35$-cycles of $94^{\circ} \mathrm{C}$ for $35 \mathrm{sec}, 55^{\circ} \mathrm{C}$ \\
& for $25 \mathrm{sec}, 72^{\circ} \mathrm{C}$ for $1 \mathrm{~min}$ \\
VEGF & $94^{\circ} \mathrm{C}$ for $3 \mathrm{~min}, 34$-cycles of $94^{\circ} \mathrm{C}$ for $30 \mathrm{sec}, 61^{\circ} \mathrm{C}$ \\
& for $31 \mathrm{sec}, 72^{\circ} \mathrm{C}$ for $1 \mathrm{~min}$
\end{tabular}

Bcl-2, B-cell lymphoma-2; Bax, Bcl-2-associated X protein; VEGF, vascular endothelial growth factor; CXCL5, C-X-C motif chemokine ligand 5; CXCR2, C-X-C chemokine receptor type 2.

effect of paracrine signaling on the growth of HepG2 cells, conditioned medium (CM) was collected as follows: The parental, empty vector-transfected and CXCL5-transfected LX-2 cells were seeded into $10-\mathrm{cm}$ plates $\left(3 \times 10^{6}\right.$ cells/plate $)$ and maintained in DMEM complete medium at $37^{\circ} \mathrm{C}$ for $48 \mathrm{~h}$. The CM was then prepared by collecting the supernatants. By using different ratios of CM $(0,20,40,60$ or $80 \%)$ dissolved in complete medium, the proliferation of HepG2 cells was determined.

Colony formation assay. HepG2 cells were plated onto a 24 -well plate $\left(2 \times 10^{2}\right.$ cells/well $)$ containing DMEM complete medium with $0,20,40,60$ or $80 \mathrm{ng} / \mathrm{ml}$ exogenous CXCL5. The same number of parental, empty vector-transfected and CXCL5-transfected HepG2 cells were also seeded in a 24-well plate maintained with DMEM complete medium. The colonies were stained with crystal violet and were counted after incubating the cells for 12 days.

Migration assays. HepG2 cells ( $1 \times 10^{4}$ cells/well) were seeded into the upper wells of Transwell ${ }^{\circledR}$ chambers (cat. no. 3422; Corning Incorporated, Corning, NY, USA) in DMEM only (without FBS); DMEM complete medium (with 10\% FBS) containing $0,20,40,60$ or $80 \mathrm{ng} / \mathrm{ml}$ of exogenous CXCL5 was added to the lower wells. For the paracrine assay, 0, 20, 40, 60 or $80 \%$ of LX-2 CM in DMEM complete medium was added to the lower wells. To perform the autocrine investigation, the parental, empty vector-transfected and CXCL5-transfected HepG2 cells were seeded into Transwell ${ }^{\circledR}$ chambers $\left(1 \times 10^{4}\right.$ cells/well) in DMEM only (without FBS); DMEM complete medium (with 10\% FBS) was added to the lower wells. After cells were incubated for $24 \mathrm{~h}$ at $37^{\circ} \mathrm{C}$, the upper surface of the membranes was scrubbed with a cotton swab to remove the cells that had not migrated. The cells attached to the lower surface of the membrane were stained with crystal violet for $30 \mathrm{~min}$ at room temperature and were counted using a light microscope (magnification, x50).

Statistical analysis. Data are expressed as the mean \pm standard deviation. The data were analyzed by q-test using SPSS 17.0 (SPSS, Inc., Chicago, IL, USA). P<0.05 was considered to indicate a statistically significant difference.

\section{Results}

CXCL5 and its receptor CXCR2 are expressed by HepG2 cells. Prior to investigating the functions of CXCL5 in HepG2 cells, the expression of CXCL5 was examined by RT-PCR and ELISA, and the expression of CXCR2 was determined by RT-PCR and western blotting. Both CXCL5 and its receptor CXCR2 were evidently expressed by HepG2 cells (Fig. 1).

Exogenous CXCL5 promotes carcinogenic potential of HepG2 cells in vitro. The proliferation assay showed that there was a significant increase in the proliferation of HepG2 cells treated with $20 \mathrm{ng} / \mathrm{ml}$ exogenous CXCL5 compared with other concentrations of exogenous CXCL5 after $48 \mathrm{~h}(\mathrm{P}<0.05)$. In addition, there was a significant increase in HepG2 cells 

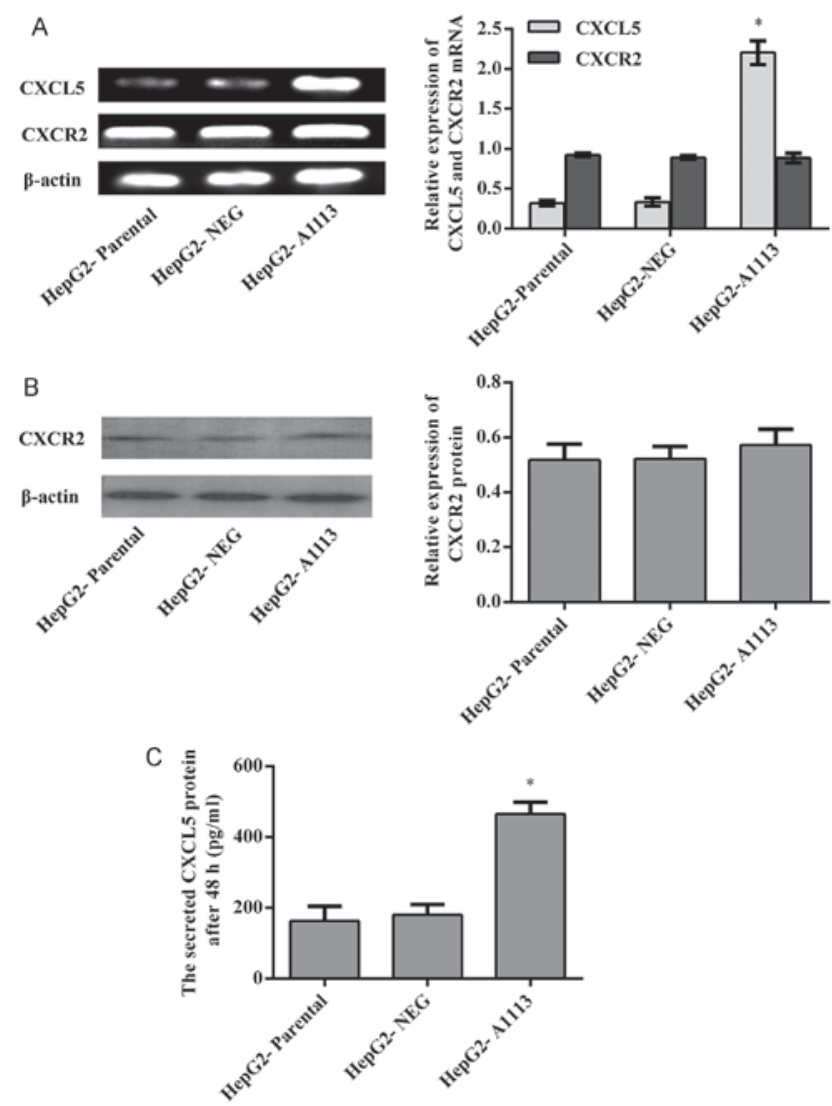

Figure 1. CXCL5 and its receptor CXCR2 are expressed by parental, HepG2-NEG and HepG2-A1113 cells. (A) CXCL5 mRNA was upregulated in HepG2-A1113 cells compared with HepG2-parental or HepG2-NEG cells. The expression levels of CXCR2 (A) mRNA and (B) protein were not significantly different in all three cell lines. (C) However, the expression of CXCL5 secretory protein was upregulated in HepG2-A1113 cells compared with HepG2-parental or HepG2-NEG cells. "P<0.05. CXCL5, $\mathrm{C}-\mathrm{X}-\mathrm{C}$ motif chemokine ligand 5; CXCR2, C-X-C chemokine receptor type 2; HepG2-NEG, empty vector-transfected HepG2 cells; HepG2-A1113, CXCL5-transfected HepG2 cells.

treated with 20 or $40 \mathrm{ng} / \mathrm{ml}$ of exogenous CXCL5 after 72 or $96 \mathrm{~h}$. It was observed that $60 \mathrm{ng} / \mathrm{ml}$ of exogenous CXCL5 exerted an inhibitory effect on proliferation at each time point, and a significant decrease on growth in HepG2 cells treated with $60 \mathrm{ng} / \mathrm{ml}$ of exogenous CXCL5 was found after $96 \mathrm{~h}$ (Fig. 2A). After 12 days of incubation, colony formation assay showed that the total colony number in HepG2 cells treated with $60 \mathrm{ng} / \mathrm{ml}$ of exogenous CXCL5 was significantly increased compared with $0,20,40$ or $80 \mathrm{ng} / \mathrm{ml}$ exogenous CXCL5 (Fig. 2B). Additionally, a significant increase in migration was observed in HepG2 cells treated with 40, 60 or $80 \mathrm{ng} / \mathrm{ml}$ exogenous CXCL5 compared with $0,20 \mathrm{ng} / \mathrm{ml}$ exogenous CXCL5 (Fig. 2C).

Overexpression of CXCL5 accelerates proliferation, colony formation and migration of HepG2 cells in vitro. To study the autocrine roles of CXCL5 on HepG2 cells, the target gene CXCL5 was successfully transfected into HepG2 cells. RT-PCR and ELISA showed that CXCL5 mRNA and protein expression in CXCL5 overexpression cells (HepG2-A1113) was significantly increased in comparison to parental cells (HepG2-parental) or empty vector expression cells
A

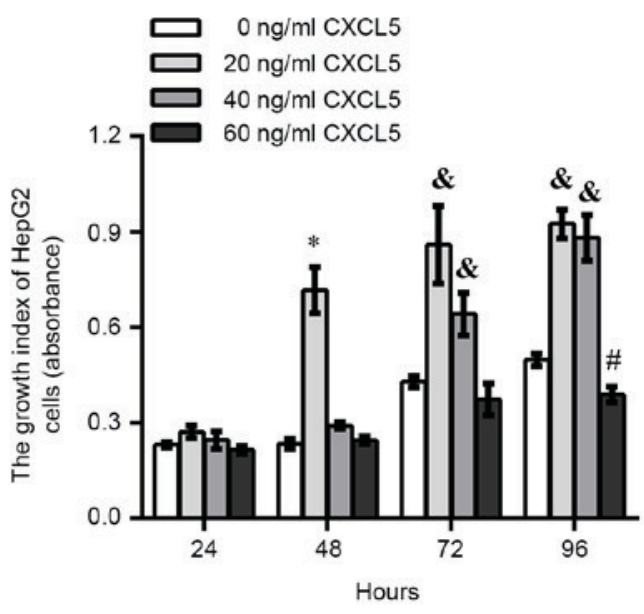

B
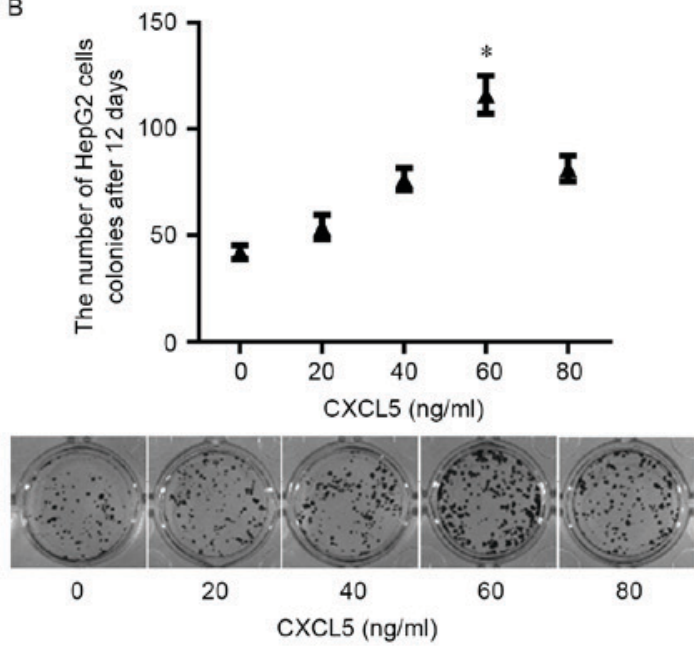

C
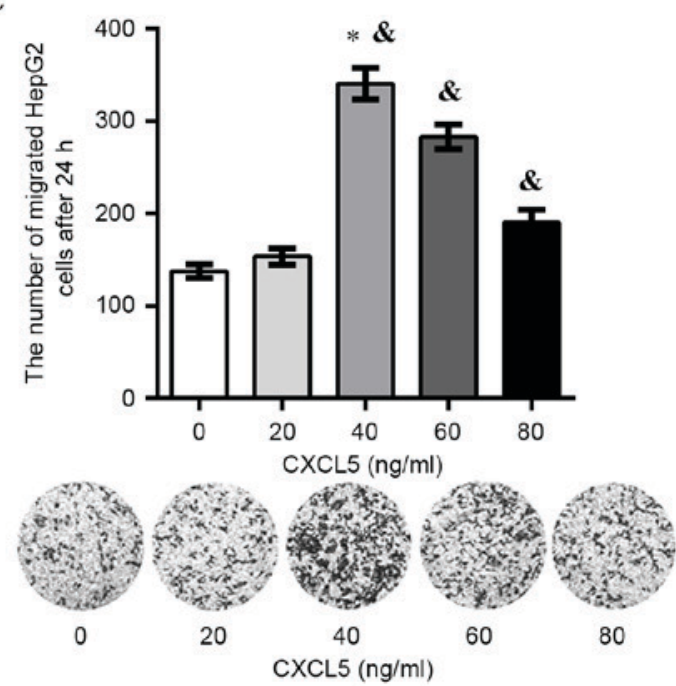

Figure 2. Exogenous CXCL5 expression contributes to the tumorigenesis of HepG2 cells in vitro. (A) Cell counting kit-8 assay showed significant growth promotion when HepG2 cells grew in medium supplemented with $20 \mathrm{ng} / \mathrm{ml}$ exogenous CXCL5 for 48,72 or $96 \mathrm{~h}$ or $40 \mathrm{ng} / \mathrm{ml}$ exogenous CXCL5 for 72 or $96 \mathrm{~h} ; 60 \mathrm{ng} / \mathrm{ml}$ exogenous CXCL5 significantly inhibited proliferation only after $96 \mathrm{~h}$ of treatment $\left({ }^{*} \mathrm{P}<0.05\right.$ vs. 0,40 or $60 \mathrm{ng} / \mathrm{ml} ;{ }^{\&} \mathrm{P}<0.05$ vs. 0 or $60 \mathrm{ng} / \mathrm{ml}$; ${ }^{\#} \mathrm{P}<0.05$ vs. 0,20 or $40 \mathrm{ng} / \mathrm{ml}$ ). (B) Treatment with $60 \mathrm{ng} / \mathrm{ml}$ exogenous CXCL5 efficiently promoted colony formation of HepG2 cells after 12 days $\left({ }^{*} \mathrm{P}<0.05\right)$. (C) Representative images indicated that exogenous CXCL5 at certain concentrations significantly enhanced the migration of HepG2 cells in a Transwell assay ( ${ }^{*} \mathrm{P}<0.05$ vs. $0,20,60$ or $80 \mathrm{ng} / \mathrm{ml}$; ${ }^{\&} \mathrm{P}<0.05$ vs. 0 or $\left.20 \mathrm{ng} / \mathrm{ml}\right)$. CXCL5, C-X-C motif chemokine ligand 5. 

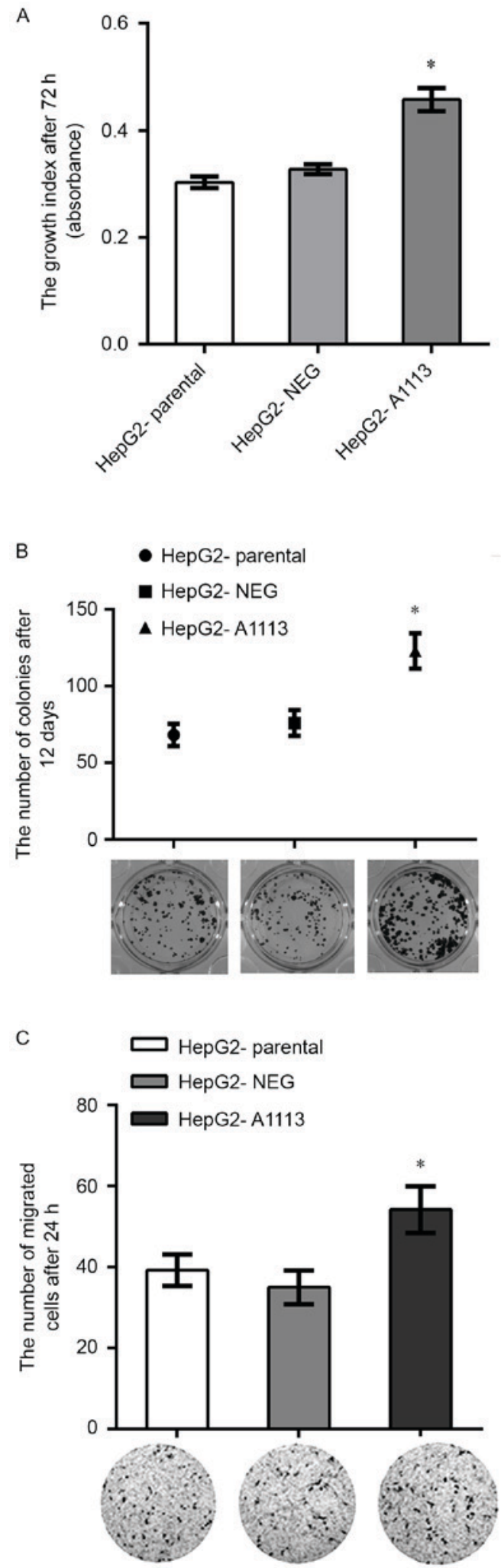

Figure 3. Overexpression of CXCL5 is positively associated with the oncogenic potential of HepG2 cells in vitro. (A) Growth, (B) colony formation and (C) migration assays showed the growth, colony formation and migration, respectively, of HepG2-A1113 cells were significantly increased compared with HepG2-parental or HepG2-NEG cells ( $\mathrm{P}<0.05)$. CXCL5, C-X-C motif chemokine ligand 5.

(HepG2-NEG) (Fig. 1A and C). HepG2-A1113 cells exhibited increased growth, colony formation and migration compared with HepG2-parental and HepG2-NEG (Fig. 3A-C).
Upregulation of CXCL5 in LX-2 cells encourages the carcinogenic potential in HepG2 cells by paracrine signaling. To investigate paracrine role of CXCL5, the identity of CXCL5 overexpression LX-2 cells (LX-2 A1113) and empty vector expression LX-2 cells (LX-2 NEG) was confirmed by RT-PCR (Fig. 4A) and ELISA assays (Fig. 4B). CCK-8 and Transwell assays showed that proliferation and migration of the HepG2 cells treated with the CM of LX-2 A1113 was significantly increased compared with the cells treated with CM from LX-2 parental or LX-2 NEG cells (Fig. 4C and D).

Overexpression of CXCL5 regulates the expression of genes in Hep 2 cells. RT-PCR showed downregulation of N-myc downregulated gene (NDRG) 3, B-cell lymphoma-2 (Bcl-2)-associated $\mathrm{X}$ protein (Bax) and P53 in HepG2-A1113 cells compared with HepG2-parental or HepG2-NEG cells. However, overexpression of CXCL5 in HepG2 cells led to upregulation of Bcl-2 and vascular endothelial growth factor (VEGF) mRNA (Fig. 5A). Western blotting indicated that the protein levels of IL-18, IL-1 $\beta$ and CSE in HepG2-A1113 cells were increased compared with HepG2-parental and HepG2-NEG cells (Fig. 5B).

\section{Discussion}

At present, the biological roles of chemokines in malignancies is diverse and the views are involved in both carcinogenesis and tumor inhibition. However, the preponderance of evidence showed that chemokines contribute mainly to carcinogenesis in the progress of cancers (19). Although CXCL5 has been reported to have numerous roles in carcinomas $(20,21)$, to the best of our knowledge, the present study was the first to conduct a paracrine secretion assay to investigate the effects of endogenous CXCL5 secreted by hepatic stellate LX-2 cells on the oncogenic potential of HB HepG2 cells. HepG2 was originally thought to be a hepatocellular carcinoma cell line and was utilized to investigate hepatocellular carcinoma. However, previous research has shown that HepG2 is a HB-derived cell line (22), which has a crucial role in studying the underlying progression and mechanism of $\mathrm{HB}(23,24)$. In the present study, it was confirmed that CXCL5 and its receptor CXCR2 are expressed in HepG2 cells. Additionally, an appropriate concentration of exogenous CXCL5 significantly promoted the proliferation and migration of HepG2 cells. It continues to be uncertain why exogenous CXCL5 at a high concentration suppressed the proliferation and migration of HepG2 cells. In the present results, overexpression of CXCL5 in HepG2 did not change the expression of CXCR2, suggesting the suppressive effects may be a result of the high concentration of CXCL5 blocking the affinity of CXCR2 to CXCL5. Since tumor cells and surrounding stromal cells may secrete chemokines that stimulate proliferation or inhibit the apoptosis of tumor cells by activating chemokine receptors on tumor cells (19), HepG2 cells overexpressing CXCL5 and LX-2 cells overexpressing CXCL5 were constructed in the present study to conduct autocrine and paracrine assays. The autocrine results showed that overexpression of CXCL5 augmented the proliferation, colony formation and migration of HepG2 cells. Similarly, in paracrine assays, the condition medium of LX-2 cells overexpressing CXCL5 stimulated the growth and migration capacities of HepG2 cells. 


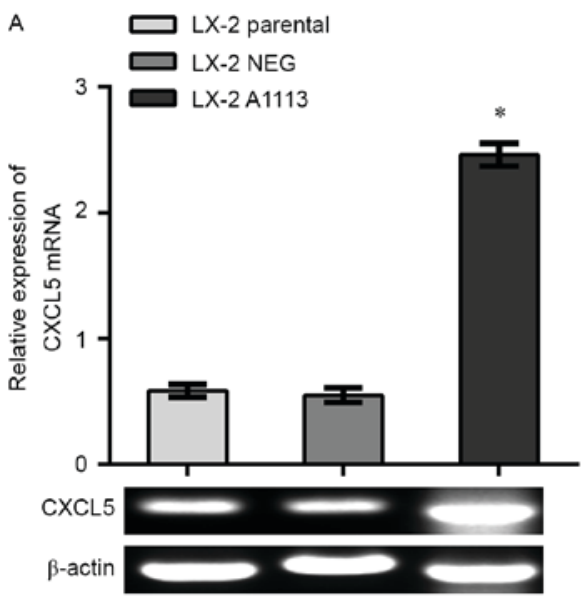

C

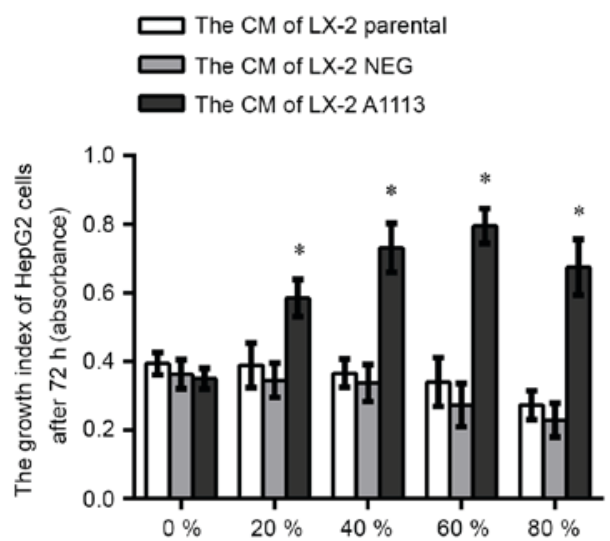

B
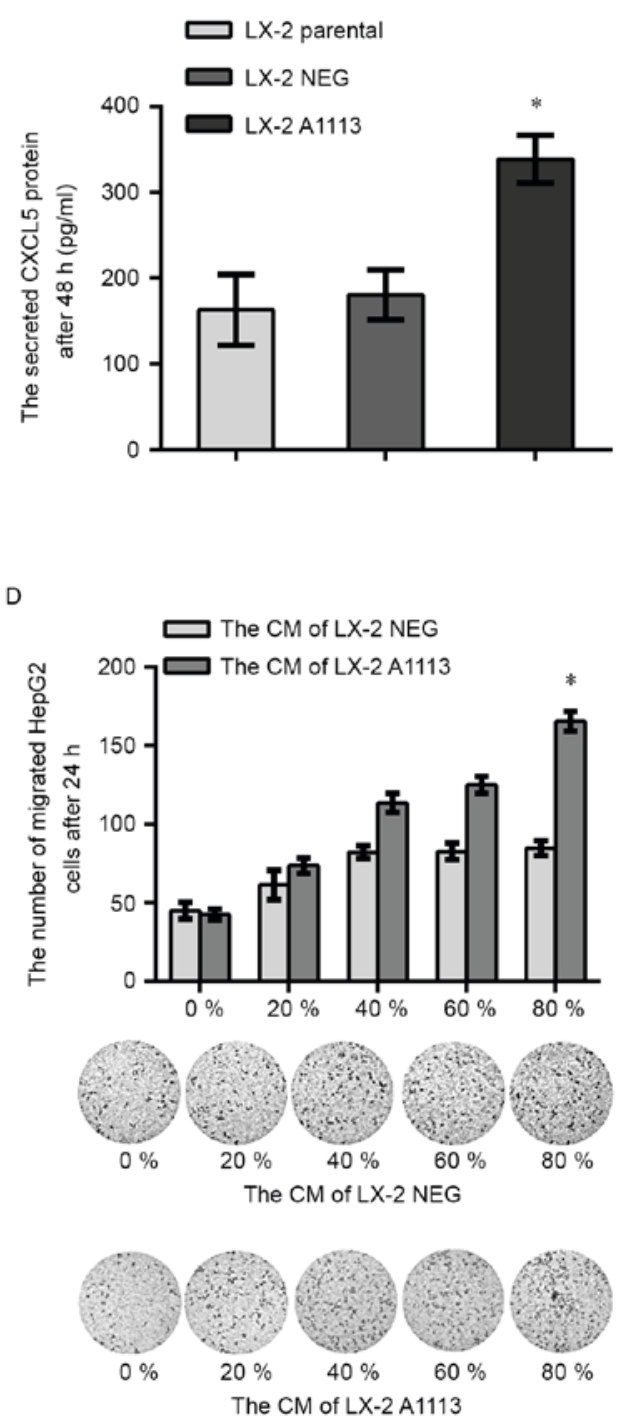

Figure 4. Upregulation of CXCL5 in LX-2 cells is involved in the proliferation and migration of HepG2 cells by paracrine signaling. CXCL5 (A) mRNA and (B) secretory protein in LX-2 A1113 cells were significantly increased compared with parental and LX-2 NEG cells ( $\mathrm{P}<0.05)$. The (C) proliferation and (D) migration capacity of HepG2 cells treated with CM from LX-2 A1113 cells were increased compared with the cells treated with CM from LX-2 parental or LX-2 NEG cells ("P<0.05). CXCL5, C-X-C motif chemokine ligand 5; LX-2 A1113, CXCL5-transfected LX-2 cells; LX-2 NEG, empty vector-transfected LX-2 cells; CM, culture medium.

Both Bax and Bcl-2, which are members of the Bcl-2 family, have multiple roles in the carcinogenesis of tumors. As cells were exposed to adverse factors, Bax can induce the process of apoptosis, by which the permeabilization of mitochondrial outer membrane is strengthened. In contrast, $\mathrm{Bcl}-2$ is a potent inhibitor of apoptosis for the reason of suppressing the activity of Bax. It was apparent that Bax and Bcl-2 had opposite effects on cell apoptosis, the balance between Bax and Bcl-2 determined the cell fate $(25,26)$. Since both downregulation of Bax and upregulation of Bcl-2 at mRNA levels were detected in HepG2 cells overexpressing CXCL5, CXCL5 in HepG2 cells might help protect against apoptosis and further exert its function on proliferation.

In addition, the present findings showed that another apoptosis-associated gene, P53, which is the upstream gene of Bax and Bcl-2, was upregulated in $\mathrm{HepG} 2$ cells overexpressing CXCL5. Previous studies suggested that in AGS human cancer cells treated with polyphenols from lyophilized A. cepa Linn, upregulation of P53 was found, which further increased the $\mathrm{Bax} / \mathrm{Bcl}-2$ ratio by disrupting the balance between Bax and Bcl-2 (27,28). Based on the aforementioned findings for Bax, Bcl-2 and p53, the present study hypothesized that CXCL5 in HepG2 cells participates in the malignant transformation of HB by downregulating P53, which decreases the ratio of Bax and $\mathrm{Bcl}-2$.

The present findings indicated that overexpression of CXCL5 can downregulate and upregulate the expression of NDRG3 and VEGF at mRNA level, respectively. NDRG3 is a member of the NDRG family, which contains 4 paralogs, consisting of NDRG1, -2, -3 and -4 (29). At present, a limited number of studies about NDRG3 have been produced. It has been found that NDRG3 may have a role in spermatogenesis, since it is found in the outer layers of the seminiferous epithelium (30). In our previous study, we identified that 

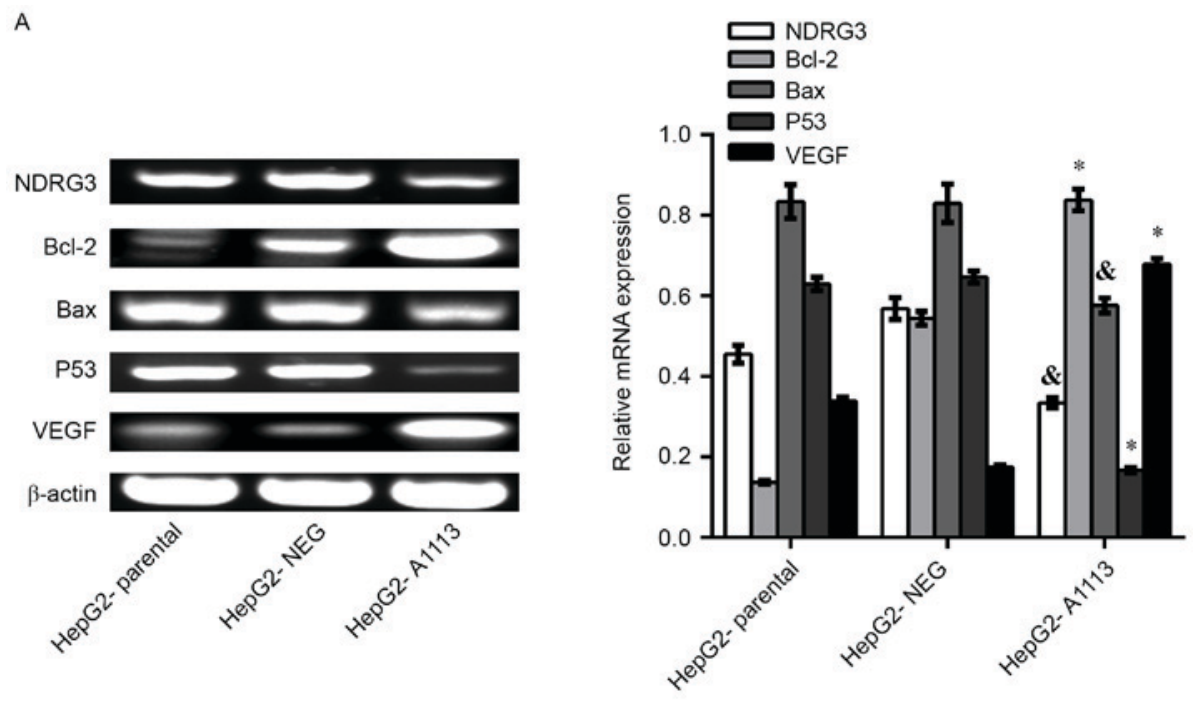

B

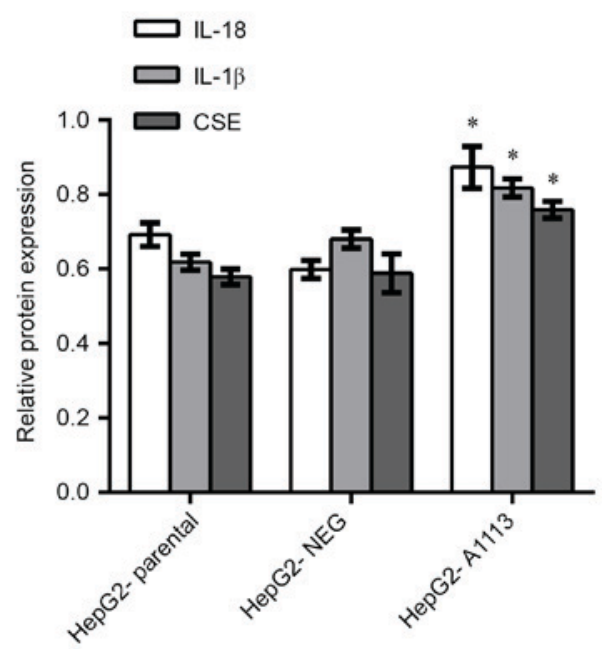

Figure 5. Overexpression of CXCL5 regulates the expression of genes in HepG2 cells. (A) In reverse transcription-polymerase chain reaction assays, downregulation of NDRG3, Bax and P53 mRNA in HepG2-A1113 cells were detected compared with HepG2-parental or HepG2-NEG cells. However, the levels of Bcl-2 and VEGF mRNA in HepG2-A1113 cells were increased. (B) Western blotting assays showed upregulation of IL-18, IL-1 $\beta$ and CSE proteins in HepG2-A1113 cells ( $\mathrm{P}<0.01$; $\left.{ }^{\&} \mathrm{P}<0.05\right)$. Bcl-2, B-cell lymphoma-2; Bax, Bcl-2-associated X protein; VEGF, vascular endothelial growth factor; IL, interleukin; CXCL5, C-X-C motif chemokine ligand 5; CSE, cystathionine- $\gamma$-lyase; HepG2-NEG, empty vector-transfected HepG2 cells; HepG2-A1113, CXCL5-transfected HepG2 cells.

NDRG3 was associated with the proliferation and migration ability of prostatic carcinoma cells in vitro and in a nude mouse xenograft model (18). Furthermore, overexpression of NDRG3 in PCa can significantly upregulate the expression of CXCL5, and the results of this study indicated that the effect of NDRG3 on tumorigenesis of PCa is partly mediated through the NDRG3/CXCL5 pathway (18). By contrast, it was also shown that overexpression of CXCL5 decreased the expression of NDRG3, suggesting there is a negative feedback mechanism in the NDRG3/CXCL5 pathway. Since NDRG3 is an androgen-dependent gene (18), it is possible that the deactivation process of estrogen may be delayed as the normal functions of hepatic cells are damaged with the development of $\mathrm{HB}$ and further lead to an increase in the estrogen/androgen ratio. As a result, the expression of the androgen-dependent gene NDRG3 will be suppressed.

VEGF has a variety of biological functions and has important roles in angiogenesis, but the significance of VEGF in tumors has yet to be fully elucidated. As demonstrated in a previous study, VEGF and its receptor kinase insert domain receptor stimulated the proliferation of gastric adenocarcinoma cells via an autocrine mechanism (31). On the basis of the aforementioned findings and the present RT-PCR data, which found overexpression of VEGF in HepG2 cells overexpressing CXCL5, the proliferation activity of CXCL5 in HB may be mediated through VEGF.

As an endogenous enzyme, CSE is crucial to the generation of $\mathrm{H}_{2} \mathrm{~S}$. Previous studies have shown that CSE is involved in a variety of physiological and tumor processes (32-34), and the knockdown of CSE by shRNA can decrease cell proliferation, migration and tumor xenograft growth in nude mice (35). Consistent with this, the present data showed that the upregulation of the CSE protein in HepG2 cells overexpressing CXCL5 is positively associated with the proliferation and migration of HepG2 cells.

It has been recognized that IL-18 has an important role in the invasion and migration of tumors by contributing to the evasion of immune recognition, producing tumor 
growth-stimulating factors and promoting angiogenesis (36). In a study investigating IL-1 $\beta$, Tu et al (37) demonstrated that IL-1 $\beta$ in transgenic mice promotes spontaneous inflammation, metaplasia, dysplasia and carcinoma; activating $\mathrm{NF}-\kappa \mathrm{B}$ through IL-1 $\beta$ enhanced gastric inflammation and promoted carcinogenesis in myeloid-derived suppressor cells. In addition, the present western blotting assay showed that the IL-18 and IL-1 $\beta$ proteins were upregulated in HepG 2 cells overexpressing CXCL5. These findings support the importance of CXCL5 in immune and inflammatory reactions of HB.

In summary, the present study demonstrated that the CXCL5/CXCR2 axis is involved in the carcinogenesis of $\mathrm{HB}$ by regulating the expression of several genes. In particular, the results of the present study demonstrated that conditional medium from CXCL5-overexpressing hepatic stellate LX-2 cells, a major stromal cell type, stimulated HB HepG2 cell proliferation and migration in a paracrine fashion, suggesting that stromal-epithelial interactions, by which cancer cells interact with their surrounding cells, are critical events in tumor microenvironment.

\section{Acknowledgements}

The present study was supported by grants from National Nature Science Foundation of China (grant no. 81272854), Nature Science Youth Foundation of Heilongjiang Province (grant no. QC2013C101), Key Research Program of Jiamusi University (grant no. Sz2009-008), Science and Innovation Team Building Project of Department of Education of Heilongjiang Province (grant no. cxtd-2016-03), President Innovation and Entrepreneurship Foundation of Jiamusi University (grant no. xzyf2014-12), and Innovation and Entrepreneurship Training Program for College Students of Heilongjiang Province (grant no. 201410222036)

\section{References}

1. Stocker JT: Hepatoblastoma. Semin Diagn Pathol 11: 136-143, 1994

2. Khaderi S, Guiteau J, Cotton RT, O'Mahony C, Rana A and Goss JA: Role of liver transplantation in the management of hepatoblastoma in the pediatric population. World $\mathbf{J}$ Transplant 4: 294-298, 2014

3. Hiyama E: Pediatric hepatoblastoma: Diagnosis and treatment. Transl Pediatr 3: 293-299, 2014.

4. Kayisli UA, Mahutte NG and Arici A: Uterine chemokines in reproductive physiology and pathology. Am J Reprod Immunol 47 213-221, 2002.

5. Murdoch C and Finn A: Chemokine receptors and their role in inflammation and infectious diseases. Blood 95: 3032-3043, 2000.

6. Kollet O, Vagima Y, D'Uva G, Golan K, Canaani J, Itkin T, Gur-Cohen S, Kalinkovich A, Caglio G, Medaglia C, et al: Physiologic corticosterone oscillations regulate murine hematopoietic stem/ progenitor cell proliferation and CXCL12 expression by bone marrow stromal progenitors. Leukemia 27: 2006-2015, 2013.

7. Koch AE: Review: Angiogenesis: Implications for rheumatoid arthritis. Arthritis Rheum 41: 951-962, 1998.

8. Selam B, Kayisli UA, Garcia-Velasco JA, Akbas GE and Arici A: Regulation of fas ligand expression by IL-8 in human endometrium. J Clin Endocrinol Metab 87: 3921-3927, 2002.

9. Milliken D, Scotton C, Raju S, Balkwill F and Wilson J: Analysis of chemokines and chemokine receptor expression in ovarian cancer ascites. Clin Cancer Res 84: 1108-1114, 2002.

10. Arenberg DA, Keane MP, DiGiovine B, Kunkel SL, Morris SB, Xue YY, Burdick MD, Glass MC, Iannettoni MD and Strieter RM: Epithelial-neutrophil activating peptide (ENA-78) is an important angiogenic factor in non-small cell lung cancer. J Clin Invest 102: 465-472, 1998.
11. Begley LA, MacDonald JW, Day ML and Macoska JA: CXCL12 activates a robust transcriptional response in human prostate epithelial cells. J Biol Chem 282: 26767-26774, 2007.

12. Murakami T, Maki W, Cardones AR, Fang H, Tun Kyi A, Nestle FO and Hwang ST: Expression of CXC chemokine receptor- 4 enhances the pulmonary metastatic potential of murine B16 melanomacells. Cancer Res 15: 7328-7334, 2002.

13. Hirbe AC, Morgan EA and Weilbaecher KN: The CXCR4/SDF-1 chemokine axis: A potential therapeutic target for bone metastases? Curr Pharm Des 16: 1284-1290, 2010.

14. Begley LA, Kasina S, Mehra R, Adsule S, Admon AJ, Lonigro RJ, Chinnaiyan AM and Macoska JA: CXCL5 promotes prostate cancer progression. Neoplasia 10: 244-254, 2008.

15. Miyazaki H, Patel V, Wang H, Edmunds RK, Gutkind JS and Yeudall WA: Down-regulation of CXCL5 inhibits squamous carcinogenesis. Cancer Res 66: 4279-4284, 2006.

16. Park JY, Park KH, Bang S, Kim MH, Lee JE, Gang J, Koh SS and Song SY: CXCL5 overexpression is associated with late stage gastric cancer. J Cancer Res Clin Oncol 133:835-840, 2007.

17. Zhou SL, Dai Z, Zhou ZJ, Wang XY, Yang GH, Wang Z, Huang XW, Fan J and Zhou J: Overexpression of CXCL5 mediates neutrophil infiltration and indicates poor prognosis for hepatocellular carcinoma. Hepatology 56: 2242-2254, 2012.

18. Wang W, Li Y, Li Y, Hong A, Wang J, Lin B and Li R: NDRG3 is an androgen regulated and prostate enriched gene that promotes in vitro and in vivo prostate cancer cell growth. Int J Cancer 124: 521-530, 2009.

19. Rollins BJ: Inflammatory chemokines in cancer growth and progression. Eur J Cancer 42: 760-767, 2006.

20. Speetjens FM, Kuppen PJ, Sandel MH, Menon AG, Burg D, van de Velde CJ, Tollenaar RA, de Bont HJ and Nagelkerke JF: Disrupted expression of CXCL5 in Colorectal cancer is associated with rapid tumor formation in rats and poor prognosis in patients. Clin Cancer Res 14: 2276-2284, 2008.

21. Xia J, Xu X, Huang P, He M and Wang X: The potential of CXCL5 as a target for liver cancer - what do we know so far? Expert Opin Ther Targets 19: 141-146, 2015.

22. López-Terrada D, Cheung SW, Finegold MJ and Knowles BB: Hep G2 is a hepatoblastoma-derived cell line. Hum Pathol 40: 1512-1515, 2009.

23. Yumnam S, Hong GE, Raha S, Saralamma VV, Lee HJ, Lee WS, Kim EH and Kim GS: Mitochondrial dysfunction and $\mathrm{Ca}(2+)$ overload contributes to hesperidin induced paraptosis in hepatoblastoma cells, HepG2. J Cell Physiol 231:1261-1268, 2016.

24. Nishikawa T, Tanaka Y, Nishikawa M, Ogino Y, Kusamori K, Mizuno N, Mizukami Y, Shimizu K, Konishi S, Takahashi Y and Takakura Y: Optimization of albumin secretion and metabolic activity of cytochrome P450 1A1 of human hepatoblastoma HepG2 cells in multicellular spheroids by controlling spheroid size. Biol Pharm Bull 40: 334-338, 2017.

25. Leibowitz B and Yu J: Mitochondrial signaling in cell death via the Bcl-2 family. Cancer Biol Ther 9: 417-422, 2010.

26. Khodapasand E, Jafarzadeh N, Farrokhi F, Kamalidehghan B and Houshmand $\mathrm{M}$ : Is Bax/ $\mathrm{Bcl}-2$ ratio considered as a prognostic marker with age and tumor location in colorectal cancer? Iran Biomed J 19: 69-75, 2015.

27. Zeren T, Inan S, Vatansever HS and Sayhan S: Significance of apoptosis related proteins on malignant transformation of ovarian tumors: A comparison between $\mathrm{Bcl}-2 / \mathrm{Bax}$ ratio and p53 immunoreactiviy. Acta Histochem 116: 1251-1258, 2014.

28. Lee WS, Yi SM, Yun JW, Jung JH, Kim DH, Kim HJ, Chang SH, Kim G, Ryu CH and Shin SC, et al: Polyphenols isolated from allium cepa L. Induces apoptosis by induction of p53 and suppression of Bcl-2 through inhibiting PI3K/Akt signaling pathway in AGS human cancer cells. J Cancer Prev 19: 14-22, 2014

29. Zhang J,Li F, Liu X, Shen L, Liu J, Su J,Zhang W, Deng Y, Wang L, Liu N, et al: The repression of human differentiation-related gene NDRG2 expression by Myc via Miz-1-dependent interaction with the NDRG2 core promoter. J Biol Chem 281: 39159-39168, 2006.

30. Zhao W, Tang R, Huang Y, Wang W, Zhou Z, Gu S, Dai J, Ying K, $\mathrm{Xie} Y$ and Mao Y: Cloning and expression pattern of the human NDRG3 gene. Biochim Biophys Acta 1519: 134-138, 2001.

31. Tian X, Meng L, Shou C and Dong Z: Coexpression of vascular endothelial growth factor and its receptor KDR on gastric adenocarcinoma MGC803 cell line and stimulation of exogenous VEGF (165) to MGC803 cells. Sci China C Life Sci 43: 88-95, 2000. 
32. Wu D, Si W, Wang M, Lv S, Ji A and Li Y: Hydrogen sulfide in cancer: Friend or foe? Nitric Oxide 50: 38-45, 2015.

33. Yin P, Zhao C, Li Z, Mei C, Yao W, Liu Y, Li N, Qi J, Wang L, Shi Y, et al: Sp1 is involved inregulation of cystathionine $\gamma$-lyase gene expression and biological function by PI3K/Akt pathway in human hepatocellular carcinoma cell lines. Cell Signal 24: 1229-1240, 2012.

34. Wang XH, Wang F, You SJ, Cao YJ, Cao LD, Han Q, Liu CF and Hu LF: Dysregulation of cystathionine $\gamma$-lyase (CSE)/hydrogen sulfide pathway contributes to ox-LDL-induced inflammation in macrophage. Cell Signal 25: 2255-2262, 2013.

35. Fan K, Li N, Qi J, Yin P, Zhao C, Wang L, Li Z and Zha X: Wnt/ $\beta$-catenin signaling induces the transcription of cystathionine- $\gamma$-lyase, a stimulator of tumor in colon cancer. Cell Signal 26: 2801-2808, 2014.
36. Palma G, Barbieri A, Bimonte S, Palla M, Zappavigna S, Caraglia M, Ascierto PA, Ciliberto G and Arra C: Interleukin 18: Friend or foe in cancer. Biochim Biophys Acta 1836: 296-303, 2013.

37. Tu S, Bhagat G, Cui G, Takaishi S, Kurt-Jones EA, Rickman B, Betz KS, Penz-Oesterreicher M, Bjorkdahl O, Fox JG and Wang TC: Overexpression of interleukin-1beta induces gastric inflammation and cancer and mobilizes myeloid-derivedsuppressor cells in mice. Cancer Cell 14: 408-419, 2008. 